\title{
SARS-CoV-2 persistence at subzero temperatures
}

\author{
Catello Scarica $^{1,2}$ (D) Lodovico Parmegiani $^{1,3} \cdot$ Laura Rienzi $^{1,4} \cdot$ Attilio Anastasi $^{1,5}$ - Danilo Cimadomo ${ }^{1,4}$. \\ Francesca Gioia Klinger ${ }^{1,6}$. Emanuele Licata ${ }^{1,7}$ • Laura Sosa Fernandez ${ }^{1,8}$ • Lucia De Santis ${ }^{1,9}$
}

Received: 26 November 2020 / Accepted: 27 January 2021 / Published online: 5 February 2021

(C) The Author(s), under exclusive licence to Springer Science+Business Media, LLC part of Springer Nature 2021

Early studies on the newly emerged coronavirus SARS-CoV2 showed viral particles can remain biologically active on inanimate surfaces, which can potentially act as fomites. However, more knowledge is needed on viral transmission to restrain further spreading of the associated COVID-19. Very recently, Marques and Domingo reviewed the publications on contamination of inert surfaces by SARS-CoV-2, reporting that the virus can survive on surfaces of various materials from hours to a few days [1]. van Doremalen et al. [2] observed that passive SARS-CoV-2 vector transmission can occur through surfaces and aerosol. The same study highlighted that a high viral bioburden can remain infectious for days on surfaces. This report has prompted the adoption of precautions and operational protocols in all medical practices to limit the risk of infection and allow regular access to clinical treatments. Riddel and colleagues [3] produced crucial evidence on survival and stability of SARS-CoV-2 under diverse

Catello Scarica

lello.scarica@gmail.com

1 Italian Society of Embryology, Reproduction and Research (SIERR), Giarre, CT, Italy

2 European Hospital, Center for Reproductive Medicine, Rome, Italy

3 GynePro Medical Centers - NextClinics International, Bologna, Italy

4 Clinica Valle Giulia, GENERA Center for Reproductive Medicine, Rome, Italy

5 Physiopathology of Human Reproduction Center, Hospital "del Delta", Lagosanto, Italy

6 Department of Biomedicine and Prevention, Section of Histology and Embryology, University of Rome "Tor Vergata", Rome, Italy

7 Physiopathology of Reproduction and Andrology Unit, Sandro Pertini Hospital, Rome, Italy

8 Embryos Fertility Center, Battipaglia, Italy

9 Department of Obstetrics \& Gynecology, IVF Unit, San Raffaele Scientific Institute, University Vita-Salute San Raffaele, Milan, Italy environmental conditions. According to their data, low temperatures enhance viral survival on surfaces. This knowledge is crucial to improve our strategies of mitigation of the infection risk. Assisted reproductive technology (ART) combines medical and laboratory procedures, to treat both patients and their reproductive cells. Liquid nitrogen $\left(\mathrm{LN}_{2}\right)$ and nitrogen vapors (NV) are routinely used to cryopreserve gametes, embryos, and gonadal tissues. This is specifically relevant to SARS-CoV-2, as $\mathrm{LN}_{2} / \mathrm{NV}$ represents a potential risk of cross-contamination [4], carrying viruses and other microorganisms.

Up to now, no cases of cross-contamination from cryostored gametes or embryos have been reported. However, concerns remain, in consideration of previous reports of hepatitis B virus transmission from cryopreserved bone marrow [5]. Enhanced vigilance is also suggested by a study in which bovine embryos became infected after experimental exposure to $\mathrm{LN}_{2}$ contaminated with bovine diarrhea virus and herpes virus-1 [6].

Cobo et al. did not detect viral sequences in $\mathrm{LN}_{2}$ used to cryopreserve samples of women with chronic HIV, HBV, and HCV undergoing ART [7]. This study is consistent with the notion of a low risk of liquid nitrogen contamination in ART. On the contrary, other studies suggest that risk of infection from $\mathrm{LN}_{2}$ cannot be entirely ruled out. In fact, while microbial analysis may fail to detect bacteria and fungi present in $\mathrm{LN}_{2}$ sample taken from contaminated dewars, the same microorganisms may be found in samples of ice and debris collected, respectively, from the lids and the bottom of the same containers [8]. This suggests that microorganisms may be present in $\mathrm{LN}_{2}$ dewars but go undetected depending on the method of analysis. To reduce the risk of contamination, some authors proposed to sterilize $\mathrm{LN}_{2}$ through filtration or UV-rays irradiation [9-11]. Concerning the latter approach, notably, most viruses are deactivated at a $200,000 \mu \mathrm{W} / \mathrm{cm}^{2}$ dose, while others are more resilient to UV irradiation. For example, the ZIKA virus results more resistant to UV-rays than the Dengue virus [12]. Reassuringly, SARS-CoV-1 is completely 
deactivated by irradiation with UVC-rays $(253 \mathrm{~nm})$ for $15 \mathrm{~min}$ at $3 \mathrm{~cm}$ [13]. The possibility that $\mathrm{LN}_{2} / \mathrm{NV}$ can become contaminated and represent a source of cross-contamination and infection raises concerns and deserves further attention. Diverse types of vitrification cryo-devices - referred to as closed systems - can prevent direct contact of specimens with $\mathrm{LN}_{2}$; pathogens may adhere to their outer surfaces but the surfaces of such devices cannot be sanitized without affecting the viability of vitrified samples. However, repeated rinsing in UV-sterilized $\mathrm{LN}_{2}$ can effectively remove microorganisms possibly present on the surface of the devices [14].

Irrespective of a possible, still unreported, impact of SARS$\mathrm{CoV}-2$ on gametes and embryos, the risk of cross-contamination from $\mathrm{LN}_{2} / \mathrm{NV}$ remains unresolved. As the Italian Society of Embryology, Reproduction and Research (SIERR), we released recommendations on precautions to adopt in the IVF laboratory in response to the COVID-19 pandemic [15]. Likewise, Alaluf et al. elaborated recommendations on re-opening of ART centers following a close-down, aiming at minimizing the risk of viral contagion and ensuring patient safety [16]. However, uncertainties and concerns raised by the pandemic demand more specific risk assessment focused on cryopreservation procedures. Maggiulli and colleagues performed a failure modes and effect analysis (FMEA), assessing potential failure modes for each phase of IVF procedures and highlighting protocol steps at higher risk of contamination from SARS-CoV-2 [17]. The authors found moderate to high risk of infection in patient-staff, staff-staff, and staff-cell interactions. To reduce such risks, they proposed the adoption of specific preventive measures, such as additional personal protective equipment and changes in the IVF laboratory procedures. Other authors focused more specifically on cryopreservation. Alteri and colleagues [18] performed a SWOT (Strengths, Weaknesses, Opportunities and Threats) analysis, highlighting possible risks to cryopreserved samples. The authors addressed several points, focusing on risks carried by infected gametes or operators/patients. However, as commented by Parmegiani and Vajta [19], a crucial piece of the story is still missing, i.e., possible contamination of $\mathrm{LN}_{2} / \mathrm{NV}$, which can occur multiple step. Recently, Adiga and colleagues reviewed the question of how to mitigate viral contamination risk, with reference to the cryopreservation of reproductive cells. They concluded that cryostorage using $\mathrm{LN}_{2}$ may involve the risk of crosscontamination by viral pathogens, suggesting the adoption of strategies to prevent the possible impact of the COVID-19 pandemic [20]. Further caution is suggested by the study of Lee et al. They observed that $1-5 \mu \mathrm{m}$ aerosol mist particles form 10-20 $\mathrm{cm}$ above the $\mathrm{LN}_{2}$-air interface, probably due to condensation, evaporation, and floating of particles. This finding should prompt increased care to $\mathrm{LN}_{2}$ handling [21]; it also poses the question of whether $\mathrm{LN}_{2} / \mathrm{NV}$ may be a vehicle of viral contamination among virus among ART laboratories.

ART centers frequently exchange cryopreserved gametes and embryos, amplifying the challenges associated with cryostorage. This makes more acute and urgent the need to define potential risks of infection derived from storage in $\mathrm{LN}_{2}$ / NV.

We believe that survival of SARS-CoV-2 at low temperatures should be more thoroughly investigated. Therefore, we encourage research groups to undertake studies aimed at testing the persistence of the virus in $\mathrm{LN}_{2} / \mathrm{NV}$ and suggest the use of sterile $\mathrm{LN}_{2}$ - as previously reported [14] — to minimize contamination risks.

\section{References}

1. Marquès M, Domingo JL. Contamination of inert surfaces by SARS-CoV-2: persistence, stability and infectivity. Environ Res: A review; 2020.

2. van Doremalen N, Bushmaker T, Morris DH, Holbrook MG, Gamble A, Williamson BN, et al. Aerosol and surface stability of SARS-CoV-2 as compared with SARS-CoV-1. N Engl J Med. 2020.

3. Riddell S, Goldie S, Hill A, Eagles D, Drew TW. The effect of temperature on persistence of SARS-CoV-2 on common surfaces. Virol J. 2020;17:145.

4. Joaquim DC, Borges ED, IGR V, Navarro PA, Vireque AA. Risk of contamination of gametes and embryos during cryopreservation and measures to prevent cross-contamination. Biomed Res Int. 2017.

5. Tedder RS, Zuckerman MA, Brink NS, Goldstone AH, Fielding A, Blair S, et al. Hepatitis B transmission from contaminated cryopreservation tank. Lancet. 1995.

6. Bielanski A, Nadin-Davis S, Sapp T, Lutze-Wallace C. Viral contamination of embryos cryopreserved in liquid nitrogen. Cryobiology. 2000.

7. Cobo A, Bellver J, De Los Santos MJ, Remohí J. Viral screening of spent culture media and liquid nitrogen samples of oocytes and embryos from hepatitis $\mathrm{B}$, hepatitis $\mathrm{C}$, and human immunodeficiency virus chronically infected women undergoing in vitro fertilization cycles. Fertil Steril. 2012.

8. Bajerski F, Bürger A, Glasmacher B, ERJ K, Müller K, Mühldorfer $\mathrm{K}$, et al. Factors determining microbial colonization of liquid nitrogen storage tanks used for archiving biological samples. Appl Microbiol Biotechnol. 2020.

9. McBurnie LD, Bardo B. Validation of sterile filtration of liquid nitrogen. Pharm Technol North Am. 2002.

10. Parmegiani L, Ge C, Bernardi S, Ciampaglia W, Fe I, C T de F, et al. Aseptic open vitrification and hermetical cryostorage of human oocytes. Hum Reprod. 2011.

11. Parmegiani L, Cognigni GE, Filicori M. Ultra-violet sterilization of liquid nitrogen prior to vitrification. Hum Reprod. 2009.

12. Lahon A, Arya RP, Kneubehl AR, Vogt MB, Dailey Garnes NJM, Rico-Hesse R. Characterization of a Zika virus isolate from Colombia. PLoS Negl Trop Dis. 2016.

13. Darnell MER, Subbarao K, Feinstone SM, Taylor DR. Inactivation of the coronavirus that induces severe acute respiratory syndrome, SARS-CoV. J Virol Methods. 2004.

14. Parmegiani L, Accorsi A, Bernardi S, Arnone A, Cognigni GE, Filicori M. A reliable procedure for decontamination before thawing of human specimens cryostored in liquid nitrogen: three washes with sterile liquid nitrogen (SLN2). Fertil Steril. 2012;98: $870-5$. 
15. De Santis L, Anastasi A, Cimadomo D, Klinger FG, Licata E, Pisaturo V, et al. COVID-19: the perspective of Italian embryologists managing the IVF laboratory in pandemic emergency. Hum Reprod [Internet]. 2020:1-2. https://doi.org/10.1093/humrep/deaa074/5817891.

16. Alaluf MG, Pasqualini A, Fiszbajn G, Botti G, Estofan G, Ruhlmann C, et al. COVID-19 risk assessment and safety management operational guidelines for IVF center reopening. J Assist Reprod Genet. 2020;37:2669-86.

17. Maggiulli R, Giancani A, Fabozzi G, Dovere L, Tacconi L, Amendola MG, et al. Assessment and management of the risk of SARS-CoV-2 infection in an IVF laboratory. Reprod Biomed Online. 2020;41:385-94.

18. Alteri A, Pisaturo V, Somigliana E, Viganò P. Cryopreservation in reproductive medicine during the COVID-19 pandemic: rethinking policies and European safety regulations. Hum Reprod. 2020;35:2650-7.

19. Parmegiani L, Vajta G. Letter: COVID-19 in liquid nitrogen: a potential danger still disregarded. Hum Reprod. 2020.

20. Adiga SK, Tholeti P, Uppangala S, Kalthur G, Gualtieri R, Talevi R. Fertility preservation during the COVID-19 pandemic: mitigating the viral contamination risk to reproductive cells in cryostorage. Reprod. Biomed. Online. 2020;41: 991-7.

21. Lee BU. Cryogenic aerosol generation: Airborne mist particles surrounding liquid nitrogen. Int J Environ Res Public Health. 2020.

Publisher's note Springer Nature remains neutral with regard to jurisdictional claims in published maps and institutional affiliations. 